\title{
Vorwort zum ersten Band
}

An dem ersten Band des Mittellateinischen Wörterbuches, der gemeinschaftlich in München und in Berlin unter der Gesamtleitung des Unterzeichneten und unter Mitarbeit von Johannes SchneIDER erstellt worden ist, haben durch Abfassung lexikalischer Artikel mitgewirkt:

In München: Gerhard BaAder, Wolfgang Hessler, Sophie Humperdinck, Theresia Payr, Willy Schetter, Renate Sroder; als ausländische Stipendiaten: Lieven van Acker, Hans F. Haefele, Pascal Ladner, Martin Steinmann, Michaela Zelzer geb. Langer, Werner Ziltener, Walter Zwimpfer.

In Berlin: Teja ERB, Ingeborg PAPE, Werner Rudolph, Peter Schmidt.

In Leipzig hat Anneliese GrAU durch Exzerpierungsarbeiten den Band gefördert.

Herrn Dr. Gustav MeYer-Basel ist für das regelmäßige Mitlesen der Korrekturfahnen bis zu seinem Ableben am 9. 3. 1966 zu danken, für Fachberatung Herrn Dr. Heinrich Marzell-Erlangen (Botanik), Herrn Dr. Wolfgang Pfeifer-Berlin (Zoologie) und Herrn Dr. Hans SchMid-München (Musikgeschichte). Daneben haben uns weitere Wissenschaftler in Einzelfragen beraten.

München, 1. Juli 1967

Otto Prinz 